\title{
Saccadic eye movement abnormalities in autism spectrum disorder indicate dysfunctions in cerebellum and brainstem
}

\author{
Lauren M Schmitt ${ }^{1}$, Edwin H Cook ${ }^{2}$, John A Sweeney ${ }^{1,3}$ and Matthew W Mosconi ${ }^{1,4^{*}}$
}

\begin{abstract}
Background: Individuals with autism spectrum disorder (ASD) show atypical scan paths during social interaction and when viewing faces, and recent evidence suggests that they also show abnormal saccadic eye movement dynamics and accuracy when viewing less complex and non-social stimuli. Eye movements are a uniquely promising target for studies of ASD as their spatial and temporal characteristics can be measured precisely and the brain circuits supporting them are well-defined. Control of saccade metrics is supported by discrete circuits within the cerebellum and brainstem two brain regions implicated in magnetic resonance (MR) morphometry and histopathological studies of ASD. The functional integrity of these distinct brain systems can be examined by evaluating different parameters of visually-guided saccades.
\end{abstract}

Methods: A total of 65 participants with ASD and 43 healthy controls, matched on age (between 6 and 44-years-old), gender and nonverbal IQ made saccades to peripheral targets. To examine the influence of attentional processes, blocked gap and overlap trials were presented. We examined saccade latency, accuracy and dynamics, as well as the trial-to-trial variability of participants' performance.

Results: Saccades of individuals with ASD were characterized by reduced accuracy, elevated variability in accuracy across trials, and reduced peak velocity and prolonged duration. In addition, their saccades took longer to accelerate to peak velocity, with no alteration in the duration of saccade deceleration. Gap/overlap effects on saccade latencies were similar across groups, suggesting that visual orienting and attention systems are relatively spared in ASD. Age-related changes did not differ across groups.

Conclusions: Deficits precisely and consistently directing eye movements suggest impairment in the error-reducing function of the cerebellum in ASD. Atypical increases in the duration of movement acceleration combined with lower peak saccade velocities implicate pontine nuclei, specifically suggesting reduced excitatory activity in burst cells that drive saccades relative to inhibitory activity in omnipause cells that maintain stable fixation. Thus, our findings suggest that both cerebellar and brainstem abnormalities contribute to altered sensorimotor control in ASD.

Keywords: Autism spectrum disorder (ASD), Sensorimotor, Eye movement, Saccade, Cerebellum, Brainstem

\footnotetext{
* Correspondence: Matt.Mosconi@UTSouthwestern.edu

${ }^{1}$ Center for Autism and Developmental Disabilities, University of Texas

Southwestern, 5323 Harry Hines Blvd, Dallas, TX 75390-9086, USA

${ }^{4}$ Departments of Psychiatry and Pediatrics, University of Texas Southwestern

Medical Center, 5323 Harry Hines Blvd, Dallas, TX 75390-9086, USA

Full list of author information is available at the end of the article
} 


\section{Background}

Impaired social communication abilities and restricted, repetitive behaviors represent the defining characteristics of autism spectrum disorder (ASD) [1]. However, the majority of affected individuals also show sensorimotor abnormalities that may precede the emergence of social communication and cognitive deficits early in life [2-5]. Improved understanding of characteristic motor deficits could therefore facilitate early detection. It also could provide insight into the pathophysiological mechanisms of ASD, as the brain systems supporting sensorimotor control are better understood than those supporting many higher-level cognitive and social processes.

In additional to atypical visual scan patterns while looking at faces and during social interactions [6-8], individuals with ASD show abnormalities in their the sensorimotor control of eye movements when viewing simple visual stimuli (illuminated dots on a blackened screen) [9-11] and human faces [12]. When making rapid shifts in eye gaze (saccades), individuals with ASD show reduced accuracy [9,13-15] and increased trial-to-trial variability of saccade accuracy $[9,13,16]$. These deficits appear to be more severe in children compared to adolescents with ASD, suggesting that the ability to precisely control eye movements may mature at a delayed rate [14]. Saccade abnormalities also are sometimes seen in unaffected family members of individuals with ASD [17], highlighting their promise as endophenotypes for parsing heterogeneity and tracking familial risk in this disorder.

Some studies of saccade dynamics in individuals with ASD have documented reduced peak velocity [15] and increased duration [12,16], while others have not $[9,13,14,18,19]$. These inconsistencies may result from differences in subject samples and methodologies across studies. Studies utilizing small samples $(\mathrm{n} \leq 15)$ may lack power to detect abnormalities that may be variably present across affected individuals $[13,15,16,19]$. For instance, one study documented abnormality in saccade dynamics, particularly in peak velocity, in one participant with ASD despite no overall group differences [19]. Moreover, some studies examined endogenously-cued or intentional saccades [12,14-16], and others examined exogenously-cued or reflexive visually-guided saccades to targets with unpredictable onset timing and spatial location $[9,11,13,18,19]$. Abnormalities in saccade dynamics have been noted consistently in tasks when subjects make endogenously-cued saccades $[15,16]$ which are under significant top-down control from the cerebral cortex [20]. Alternatively, studies of visually-guided saccades have had less consistent findings, perhaps due to testing only small saccades in some studies, as deficits appear greater in larger saccades $[17,18]$. Only one study examined the acceleration and deceleration of visually-guided saccades, however, healthy control and ASD groups did not significantly differ
[13]. These results may suggest that saccade dynamics are only affected when cortical brain structures are involved. However, it is also possible that the small sample sizes and saccade amplitudes examined in previous studies may have limited sensitivity to detect abnormalities within cerebellar and brainstem structures supporting these functions. Furthermore, in contrast to saccade accuracy, there is less evidence supporting developmental improvement in saccade dynamics in both healthy [21,22] and ASD samples during childhood and adolescence [14]. However, one study examining healthy controls across lifespan demonstrated increased peak saccade velocity from early childhood to adolescence, and subsequent decline in late adulthood [23]. With few studies examining the developmental changes of saccade dynamics in individuals with ASD, and inconsistent findings in healthy populations, a better understanding of these possible age-related changes is needed.

Saccadic eye movements are controlled by highly specialized cortico-cerebellar-brainstem circuitry [24]. Saccade initiation occurs when pontine burst cells are simultaneously released from their tonic inhibition by omnipause cells and driven by excitatory signals from the superior colliculus $[24,25]$. Thus, the process of reflexive saccade initiation requires a temporally synchronized excitation of burst cells and release of those burst cells from tonic inhibitory input. The reverse of this process terminates saccades. Dynamic characteristics of saccades including their duration, peak velocity, acceleration and deceleration depend on the firing rates of pontine burst cells in the context of their release from omnipause cell inhibition [26].

Medioposterior lobules VI to VII of the cerebellum and the caudal fastigial nuclei to which they project act to maintain saccade accuracy, compensating for any systematic error via feedforward input to the brainstem, permitting precise refocusing of the fovea onto objects of interest [26-29]. In addition, saccade error can be partially corrected online, primarily via lobules VI-VII of cerebellum, by reducing or extending the deceleration phase of saccades [30-33]. Thus, both pontine brainstem nuclei and the cerebellum regulate specific aspects of saccades that can be evaluated relatively independently in order to identify functional abnormalities in these two brain regions.

The brainstem and cerebellum have been implicated in postmortem and magnetic resonance imaging (MRI) studies of ASD. Structural MRI studies have demonstrated pontine alterations that might cause eye movement abnormalities [34-38]. Postmortem studies show reduced numbers of Purkinje cells in the cerebellar vermis, hemispheres and deep nuclei [36,39-42], as well as reduced cell counts in the fastigial nuclei [43]. Structural MRI studies have documented reduced grey matter volume within the cerebellar cortex [44] and hypoplasia of the cerebellar vermis lobules VI -VII $[45,46]$. Reduced activation in the cerebellum during saccades has been reported in a functional 
MRI study [11]. Our group and others have recently demonstrated compromised cerebellar-dependent saccade adaptation in ASD, which provides perhaps the most direct neurobehavioral evidence of dysfunction within the cerebellar vermis $[47,48]$.

Gap/overlap paradigms are useful for examining saccade latencies during conditions with different levels of fixations on a central cue $[49,50]$. This has been shown to be sensitive to saccade abnormalities in infants at risk for ASD [4], and is likely to some degree to be influenced by factors associated with visual attention linked to visual fixation. However, the extent to which latency differences are due to attentional versus oculomotor processes remains a topic of debate [51-53]. Previous studies in ASD using gap/overlap paradigms have yielded mixed results, with one showing no abnormality in the overlap effect in participants with ASD [54], and the other showing a reduced overlap effect [55]. Thus, the level of alteration in visual attentional engagement in ASD remains equivocal.

The current study aimed to examine the accuracy and dynamics of reflexive saccadic eye movements in a relatively large sample of individuals with ASD across a broad age range in order to evaluate the functional integrity of cerebellar and brainstem circuitry supporting distinct sensorimotor components of saccade control. Our secondary aim was to examine the effect of manipulating attentionshifting processes on saccade latencies utilizing gap/overlap paradigms. We hypothesized that individuals with ASD would show deficits in saccade accuracy, as well as impairments in saccade dynamics, based upon anatomical findings in the cerebellar and brainstem systems that support these functions respectively. We also hypothesized that attentional deficits would contribute to saccade initiation abnormalities in ASD.

\section{Methods \\ Participants}

A total of 65 individuals with ASD and 43 healthy controls matched in age (between 6 and 44-years-old), gender ratio and nonverbal IQ were examined (Table 1). As the oculomotor task placed minimal verbal demands on participants, we matched the ASD and control groups on nonverbal IQ as opposed to verbal ability. We have used this approach previously $[9-11,47]$ in order to include a more representative sample of individuals with ASD who are known to have more severe verbal deficits compared to nonverbal deficits [56] and large discrepancies between verbal and nonverbal abilities [57,58]. Participants with ASD were recruited from outpatient clinics at the University of Illinois at Chicago Medical Center and via flyers posted in the community. A diagnosis of ASD, including autistic disorder, Asperger's syndrome or pervasive developmental disorder-not otherwise specified (PDD-NOS) was established using the Diagnostic and Statistical Manual of Mental Disorders, Fourth Edition, Text Revision (DSM-IVTR) criteria, as confirmed by research reliably trained clinicians using the Autism Diagnostic Interview-Revised (ADI-R; [59]), the Autism Diagnostic Observation Schedule (ADOS; [60]) and by expert clinical opinion (EC, $\mathrm{MM}$ ). The participants with ASD were excluded if they had a genetic disorder associated with ASD (such as Fragile $\mathrm{X}$ syndrome) or a medical history of non-febrile seizures.

Healthy community controls were recruited through newspaper advertisements. All had a score of less than or equal to 8 on the Social Communication Questionnaire [62]. Healthy controls were excluded if they reported a personal history of psychiatric illness, a first-degree relative with a major psychiatric illness (such as schizophrenia), or a first- or second-degree relative with ASD. No participants had a previous head injury resulting in loss of consciousness, were taking any medications known to affect oculomotor function including stimulants, anticonvulsants or antipsychotics [63], consumed caffeine within 24 hours of testing, used nicotine within one hour prior to testing or had corrected far visual acuity of less than 20/40. Individuals completed the Differential Ability Scales ([64]; $\mathrm{N}=75$; <18-years-old) or Wechsler Abbreviated Scale of Intelligence ([65]; $\mathrm{N}=33$; $\geq 18$-years-old) to assess intellectual abilities. Individuals with a full-scale IQ score of under 80 were not included. Adult participants provided written consent and minors provided assent in addition to written consent from their legal guardian. This study was approved by the Institutional Review Board of the University of Illinois at Chicago (Protocol \#2002-0286 and \#2007-0239).

\section{Procedures}

Participants were tested in a darkened black room and positioned in a chin-rest with forehead and occipital restraints to minimize head movement. They were seated $60 \mathrm{~cm}$ from a 40-inch anti-glare LCD screen monitor (Samsung SyncMaster 400P; Samsung, Seoul, Korea) with a resolution of $1024 \times 768$ and a $75 \mathrm{~Hz}$ refresh rate. Electrodes placed at the lateral and nasal canthi of each eye and above and below the left eye monitored saccadic eye movements and blinks, respectively, using direct current electro-oculography (EOG; Grass Neurodata 12 Acquisition System; Astro-Med, Inc, West Warwick, Rhode Island, United States). We elected to use EOG rather than infrared recording in order to assess larger amplitude saccades (20 to 30 degrees), which our group and others have shown to be more severely impaired in ASD [13,17]. EOG signals were digitized at $500 \mathrm{~Hz}$ with a 12-bit A/D converter (DI-720 from Dataq Instruments, Akron, Ohio, United States). Visual stimuli subtending 0.5 degrees of visual angle were presented in the horizontal plane at eye level (Flash MX Actionscript 2; Adobe Systems, San Jose, California, United States). 
Table 1 Demographic characteristics for participants with ASD and healthy controls

\begin{tabular}{|c|c|c|c|}
\hline Demographic characteristic & Age group & ASD $(N=65)$ & Control $(\mathrm{N}=43)$ \\
\hline \multirow[t]{4}{*}{ Age group (n, \%) } & $6-11$ & $26(40)$ & $15(35)$ \\
\hline & $12-18$ & $23(35)$ & $12(28)$ \\
\hline & $19+$ & $16(25)$ & $16(37)$ \\
\hline & Total & 65 & 43 \\
\hline \multirow[t]{4}{*}{ Age in years } & $6-11$ & $9.4(1.4)$ & $9.0(1.6)$ \\
\hline & $12-18$ & $14.0(1.8)$ & $14.1(2.0)$ \\
\hline & $19+$ & $26.3(7.4)$ & $26.1(5.1)$ \\
\hline & Total & $15.2(7.7)$ & $16.8(8.3)$ \\
\hline \multirow[t]{4}{*}{ Gender (\% male) } & $6-11$ & 73 & 73 \\
\hline & $12-18$ & 87 & 67 \\
\hline & $19+$ & 88 & 81 \\
\hline & Total & 82 & 74 \\
\hline \multirow[t]{4}{*}{ Full scale IQ } & $6-11$ & $100(17)^{*}$ & $113(15)$ \\
\hline & $12-18$ & $94(19)^{*}$ & $107(15)$ \\
\hline & $19+$ & $102(18)$ & $110(8)$ \\
\hline & Total & $98(18)^{* *}$ & $110(13)$ \\
\hline \multirow[t]{4}{*}{ Verbal IQ } & $6-11$ & $99(16)^{* *}$ & $116(19)$ \\
\hline & $12-18$ & $93(22)^{*}$ & $110(16)$ \\
\hline & $19+$ & $109(22)$ & 109 (13) \\
\hline & Total & $99(21)$ & $106(12)$ \\
\hline \multirow[t]{4}{*}{ Nonverbal IQ } & $6-11$ & $102(18)$ & $109(16)$ \\
\hline & $12-18$ & $99(19)$ & $98(10)$ \\
\hline & $19+$ & $100(22)$ & $109(8)$ \\
\hline & Total & $100(20)$ & $106(12)$ \\
\hline \multirow[t]{4}{*}{ ADOS Totalt } & $6-11$ & $12.6(5.7)$ & \\
\hline & $12-18$ & $10.7(3.4)$ & \\
\hline & $19+$ & $9.8(4.1)$ & \\
\hline & Total & $11.2(4.7)$ & \\
\hline \multirow[t]{4}{*}{ ADI social total } & $6-11$ & $19.9(5.8)$ & \\
\hline & $12-18$ & $21.5(4.9)$ & \\
\hline & $19+$ & $17.8(6.9)$ & \\
\hline & Total & $20.0(5.8)$ & \\
\hline \multirow[t]{4}{*}{ ADI communication total } & $6-11$ & $16.2(4.6)$ & \\
\hline & $12-18$ & $16.9(4.4)$ & \\
\hline & $19+$ & $13.3(5.8)^{\mathrm{a}}$ & \\
\hline & Total & $15.8(4.9)$ & \\
\hline \multirow[t]{4}{*}{ ADI repetitive behavior total } & $6-11$ & $6.5(2.6)$ & \\
\hline & $12-18$ & $5.9(2.4)$ & \\
\hline & $19+$ & $4.8(2.0)$ & \\
\hline & Total & $5.9(2.4)$ & \\
\hline
\end{tabular}

Means (SDs) are presented for age and IQ.

${ }^{*} P<0.05$; ** $P<0.01$.

tADOS totals are based on revised algorithms [61] except for those participants $(n=22)$ who completed Module 4.

aParticipants with ASD in the 19 years of age and older age band have significantly lower ADI Communication Total scores than those in the 12 to 18 -years-old age band $(P=0.040)$.

ASD, autism spectrum disorder; IQ, intelligence quotient; ADOS, Autism Diagnostic Observation Scale; ADI, Autism Diagnostic Interview-Revised. 
Digital finite impulse response filters with non-linear transition bands were applied with a gradual transition band (from pass to no pass) between 20 and $65 \mathrm{~Hz}$ for velocity and position data, and between 30 and $65 \mathrm{~Hz}$ for acceleration data. Data from each trial were visually inspected offline and scored without knowledge of participant characteristics. Trials were assessed to determine the presence of confounding measurements (such as excessive noise in the signal, large head movements or failed task compliance). If the scorer judged any of these factors to be present, the trial was omitted from analyses.

All participants completed a visually-guided saccade task consisting of one block of 30 gap trials and one block of 30 overlap trials. The order of gap and overlap blocks was counterbalanced across participants. Gap trials included a $200 \mathrm{~ms}$ temporal gap between central fixation offset and peripheral target onset. In overlap trials, the central fixation target remained present for $200 \mathrm{~ms}$ after peripheral target onset. Trials began with a central target appearing for 1.5 to 2.5 seconds (varied randomly in $200 \mathrm{~ms}$ intervals). Peripheral targets were presented for 1.5 seconds at unpredictable locations 10, 20 or 30 degrees to the right or left of center fixation. Participants were instructed to look towards the peripheral target when it appeared.

Trials were calibrated independently using fixation data of central and peripheral target locations. Each trial was manually calibrated by marking stable center fixation prior to trial onset, and at the target location after the participant acquired the peripheral target. If signal drift or head movement occurred during the performance of the task, trials were recalibrated using within-trial data from fixation of targets of interest as we have done previously $[9,17,18,66-69]$. Saccade onset and offset were marked when eye velocity rose above and below 30 degrees per second, respectively. Saccades with latencies less than 70 ms were considered anticipatory and not included in analyses. Trials in which blinks occurred between $100 \mathrm{~ms}$ prior to stimulus presentation and the end of the primary saccade were not included.

The latency, accuracy and dynamics were measured for each saccade (Figure 1). Latencies were calculated based on the difference between peripheral target onset and saccade initiation. Saccade accuracy was examined using the absolute value of the spatial error in degrees of primary saccades relative to peripheral target position. We measured the absolute value of spatial error between primary saccade amplitude and target location because we have previously observed both hypometric (target undershoot) and hypermetric (target overshoot) saccades in participants with ASD [9]. The mean number of saccades made to acquire the peripheral targets was computed for each individual.

The peak velocity and duration of each saccade were measured. As the velocity and duration of saccades increase

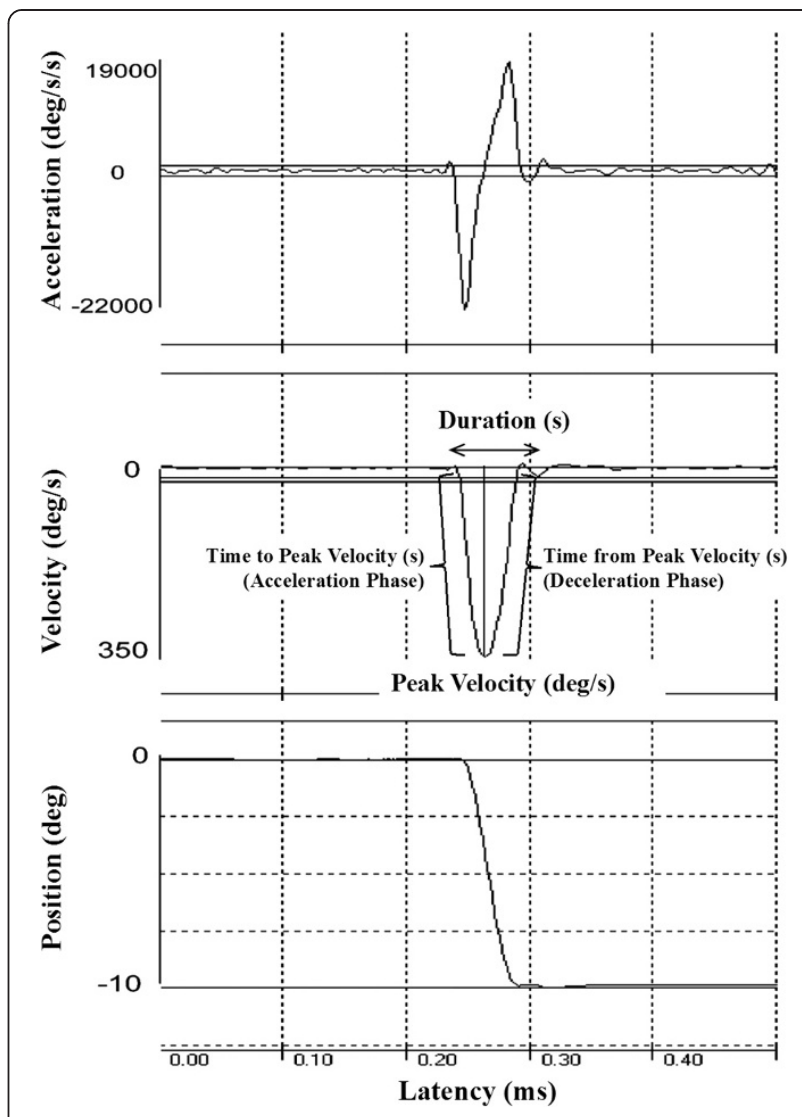

Figure $1 \mathrm{~A}$ representative sample of position (bottom), velocity (middle) and acceleration/deceleration (top) traces of a single visually-guided saccade. Parameters used to define the dynamics of each saccade, including the peak velocity and duration of the movement, and the acceleration and deceleration phases of the movement are shown in the velocity trace. Deg, degrees; $s$, seconds.

with increasing saccade amplitudes according to a 'main sequence' [70], we also examined velocity:amplitude and duration:amplitude relationships. We compared the slopes of both the velocity:amplitude and duration:amplitude relationships to identify between-group differences. In addition, we measured peak acceleration, peak deceleration, the time from saccade onset to peak saccade velocity (duration of saccade acceleration) and the time from peak saccade velocity to the end of the saccade (duration of saccade deceleration). Lastly, we examined variability of saccade accuracy, velocity, duration, acceleration, deceleration, the durations of saccade acceleration and deceleration and latency by calculating their standard deviation across trials for each subject.

We used a series of $2 \times 3 \times 2$ analysis of variance to examine the effects of diagnostic group (ASD versus control), target location $\left(10^{\circ}\right.$ versus $20^{\circ}$ versus $\left.30^{\circ}\right)$ and condition (gap versus overlap) on saccade performance. No effects of the direction of eye movements or interactions between saccade direction and diagnostic group 
were seen, therefore trials were collapsed across rightward and leftward target displacements. To examine saccade performance across development, we contrasted group differences at three different developmental stages (childhood: 6 to 11 years of age versus adolescence: 12 to 18 years of age versus adulthood: 19 and older), which were chosen based on our previous work investigating developmental trajectories of motor performance in ASD relative to healthy individuals [71].

\section{Results}

\section{Latency}

As expected, the latencies of saccades during overlap trials were longer than those during gap trials (Table 2; F $(1,104)=297.81 ; P<0.001)$. The extent to which overlap trial saccades were delayed relative to gap trial saccades did not differ between groups $(\mathrm{F}(1,104)=2.63 ; P=0.108)$. No differences in mean saccade latencies were seen between participants with ASD and healthy controls

Table 2 Saccade accuracy and latencies for participants with ASD and healthy controls

\begin{tabular}{lcr}
\hline & ASD & \multicolumn{1}{c}{ Control } \\
\hline Saccade error (absolute value in degree of visual angle) \\
$10 \mathrm{deg}$ & $1.46(0.43)^{*}$ & $1.27(0.07)$ \\
$20 \mathrm{deg}$ & $2.40(0.72)^{* * *}$ & $1.86(0.11)$ \\
$30 \mathrm{deg}$ & $3.33(1.12)^{* *}$ & $2.60(0.17)$
\end{tabular}

Trial-wise variability (SD) of saccade error (absolute value in degrees)

$\begin{array}{lll}10 \text { deg } & 1.11(0.37) & 1.03(0.37) \\ 20 \text { deg } & 1.90(0.58)^{* * *} & 1.31(0.58) \\ 30 \text { deg } & 2.79(0.58)^{* *} & 2.07(0.29)\end{array}$

Saccade amplitude in degrees

$\begin{array}{lll}10 \mathrm{deg} & 9.78(0.82) & 9.69(0.82) \\ 20 \mathrm{deg} & 19.11(1.28) & 19.20(1.28) \\ 30 \mathrm{deg} & 27.71(1.68) & 28.14(1.68)\end{array}$

Trial-wise variability (SD) of saccade amplitude in degrees

$\begin{array}{lll}10 \text { deg } & 1.91(0.64) & 1.86(0.65) \\ 20 \text { deg } & 2.75(0.83)^{*} & 2.30(0.83) \\ 30 \text { deg } & 3.86(1.19)^{* * *} & 2.10(1.19)\end{array}$

Saccade latency in ms

$\begin{array}{lll}10 \text { deg } & 255(52) & 248(52) \\ 20 \text { deg } & 275(58) & 273(58) \\ 30 \text { deg } & 313(55) & 300(55)\end{array}$

Trial-wise variability (SD) of saccade latency in ms

$\begin{array}{lll}10 \text { deg } & 80(30)^{* *} & 64(21) \\ 20 \text { deg } & 90(37)^{* *} & 66(37) \\ 30 \text { deg } & 90(32)^{*} & 75(32)\end{array}$

Mean (SD).

${ }^{*} P<0.05$; **P $<0.01$; *** $P<0.001$.

ASD, autism spectrum disorder; SD, standard deviation; ms, milliseconds; deg, degrees.
$(\mathrm{F}(1,104)=0.57 ; \quad P=0.454)$, however participants with ASD showed greater trial-to-trial variability in their saccade latencies (Figure 2; F $(1,103)=9.90 ; P=0.002$ )

\section{Accuracy}

Participants with ASD and healthy controls had similar mean amplitudes of primary saccades $(\mathrm{F}(1,104)=0.47$; $P=0.496)$, but trial-wise variability of primary saccade amplitudes was increased in $\operatorname{ASD}(\mathrm{F}(1,103)=12.44$; $P=0.001)$, especially for larger saccades $(\mathrm{F}(2,102)=15.31$; $P<0.001)$. Participants with ASD demonstrated an increase in the absolute error of their saccades, thus showing reduced accuracy (Table 2; Figure 3; $F(1,104)=17.40$; $P<0.001)$. This deficit was more severe at larger target step amplitudes $(F(2,103)=4.23 ; P=0.024)$. ASD participants also showed greater trial-to-trial variability of saccade error (Figure $3 ; \mathrm{F}(1,103)=19.13 ; P<0.001)$, which was again more pronounced at larger target step amplitudes (F $(2,102)=5.17 ; P=0.014)$. Thus, increased saccade variability reflected both saccade under-shooting and overshooting rather than consistent hypo- or hypermetria.

\section{Number of corrective saccades}

As the number of saccades made to acquire targets was non-normally distributed, non-parametric tests were used to test for group differences. Individuals with ASD and controls did not differ in the number of saccades made to acquire peripheral targets, regardless of the size of target displacement (Mann-Whitney $U$ test $=1353 ; P=0.780$ ).

The number of saccades made to acquire the target was related to saccade error (ASD: Spearman's rank correlation coefficient, or Spearman's rho $=0.28 ; P=0.025$; control: rho $=0.48 ; P=0.001)$ and error variability across trials (ASD: rho $=0.28 ; P=0.026$; control: rho $=0.35 ; P=0.034$ ) in both groups. Thus, as expected, participants with ASD and healthy controls with greater saccade error and error variability made more saccades to acquire peripheral targets.

\section{Saccade dynamics}

Peak saccade velocities were reduced in ASD (Table 3; Figure 4; $F(1,103)=3.98 ; P=0.049)$. This deficit was still evident after correcting velocity measures for saccade amplitudes $(\mathrm{F}(1,102)=5.24 ; P=0.024)$, thus, the velocity reduction did not result from smaller amplitude saccades in the patient group. Peak saccade velocity was not related to accuracy or variability of accuracy in either group (Additional files 1 and 2; P's >0.077). The variability of peak velocities across trials was not different between groups $(\mathrm{F}(1,100)=0.10 ; P=0.754)$.

Saccade duration was increased in participants with ASD compared to controls (Figure $4 ; \mathrm{F}(1,104)=4.17 ; P=0.044$ ). The ratio of saccade duration:amplitude also was elevated in participants with $\mathrm{ASD}(\mathrm{F}(1,104)=8.11 ; P=0.005)$, 


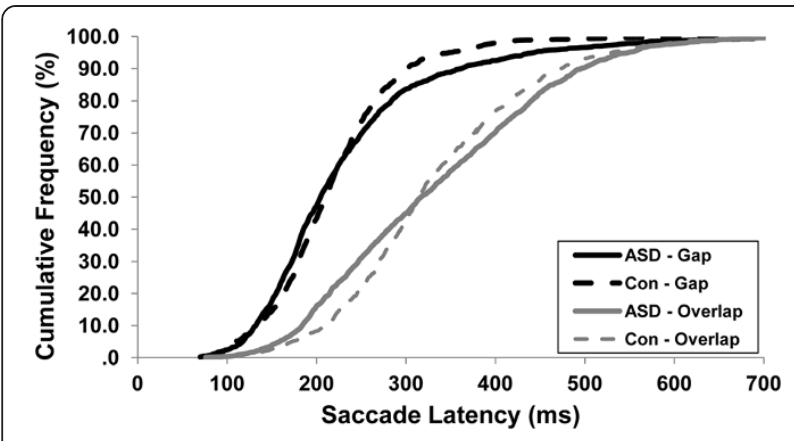

Figure 2 Cumulative frequency plot of gap and overlap saccade latencies for participants with ASD and healthy controls. Saccade latencies for overlap trials were significantly greater across participants. The extent to which latencies increased did not differ between groups, but latency variability was increased in ASD. ASD, autism spectrum disorder; Con, control.
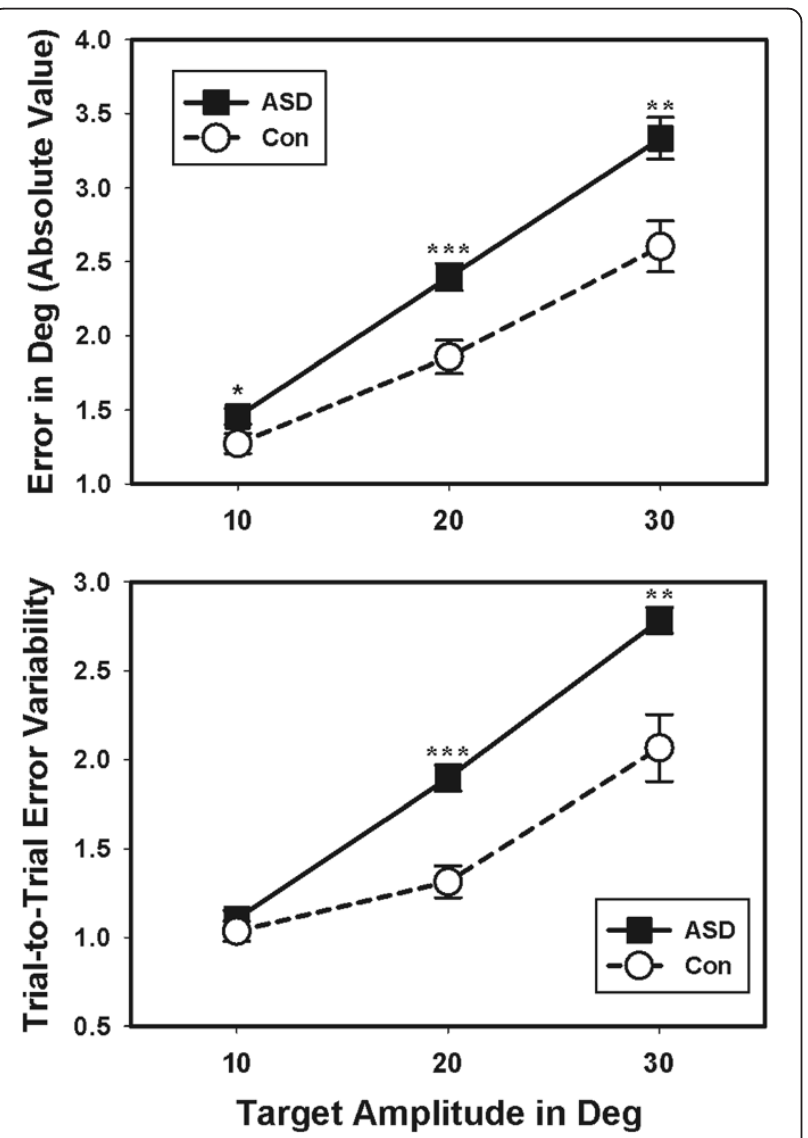

Figure 3 Individuals with ASD showed reduced accuracy of saccades compared to healthy controls. Absolute error of saccades in degrees of visual angle was increased in individuals with ASD (top). Individuals with ASD also demonstrated increased trial-to-trial variability of saccade accuracy compared to controls (bottom). Both abnormalities were greater for larger saccades at 20 and 30 degrees compared to 10 degrees. ${ }^{*} P<0.05$; ${ }^{* *} P<0.01$; ${ }^{* *} P<0.001$. ASD, autism spectrum disorder; Con, control; Deg, degrees.
Table 3 Saccade dynamics for participants with ASD and healthy controls

\begin{tabular}{lll}
\hline & ASD & Control \\
\hline Peak velocity (deg/s) & $302(46)^{*}$ & $317(44)$ \\
10 deg & $418(64)^{*}$ & $442(62)$ \\
20 deg & $465(77)$ & $478(74)$ \\
30 deg & & \\
Saccade duration (ms) & $61(11)^{* *}$ & $56(10)$ \\
10 deg & $80(11)$ & $77(10)$ \\
20 deg & $107(17)^{*}$ & $103(16)$ \\
30 deg & & \\
Peak acceleration (deg/s/s) & $20399(615)$ & $21850(747)$ \\
10 deg & $24025(646)$ & $25697(785)$ \\
20 deg & $25865(695)$ & $26746(844)$ \\
30 deg & & $27.26(5.84)$ \\
Duration of acceleration (ms) & $29.93(5.85)^{* *}$ & $35.01(6.14)$ \\
10 deg & $37.07(6.14)^{*}$ & $43.46(8.40)$ \\
20 deg & $47.26(8.40)^{*}$ & \\
30 deg & & $18383(820)$ \\
Peak deceleration (deg/s/s) & $17997(561)$ & $18849(681)$ \\
10 deg & $19756(627)$ & $20373(762)$ \\
20 deg & $19188(674)$ & $16.58)$ \\
Duration of deceleration (ms) & & \\
10 deg & $33.58(5.58)$ & \\
30 deg & $45.46(6.87)$ & \\
\hline deg & $61.77(11.01)$ & \\
\hline & & \\
\hline
\end{tabular}

Mean (SDs). ASD, autism spectrum disorder; Deg, degrees; Deg/s, degrees per second; Ms, milliseconds; Deg $/ \mathrm{s} / \mathrm{s}$, degrees per second per second. ${ }^{*} P<0.05 ;{ }^{*} P<0.01$.

particularly at smaller target step amplitudes $(\mathrm{F}(2,100)=$ 4.38; $P=0.015)$. Saccade duration was not related to accuracy or variability of accuracy in either group ( $\left.P^{\prime} \mathrm{s}>0.109\right)$. The trial-to-trial variability of saccade duration did not differ between groups $(\mathrm{F}(1,103)=2.88 ; P=0.093)$.

Although mean ratios of saccade velocity:amplitude and saccade duration:amplitude were significantly reduced and elevated in individuals with ASD, respectively, we found no group differences in the slopes of the saccade main sequence with either parameter (Additional file 3; $P$ 's $>0.429$ ). Thus, individuals with ASD demonstrated abnormalities in velocity and duration that were consistent across saccade amplitudes.

\section{Acceleration and deceleration of saccades}

Individuals with ASD and healthy controls had similar peak saccade accelerations $(F(1,102)=0.06 ; P=0.804)$ and decelerations $(F(1,102)=0.2 .02 ; P=0.158)$. There was also no difference in trial-wise variability of peak 


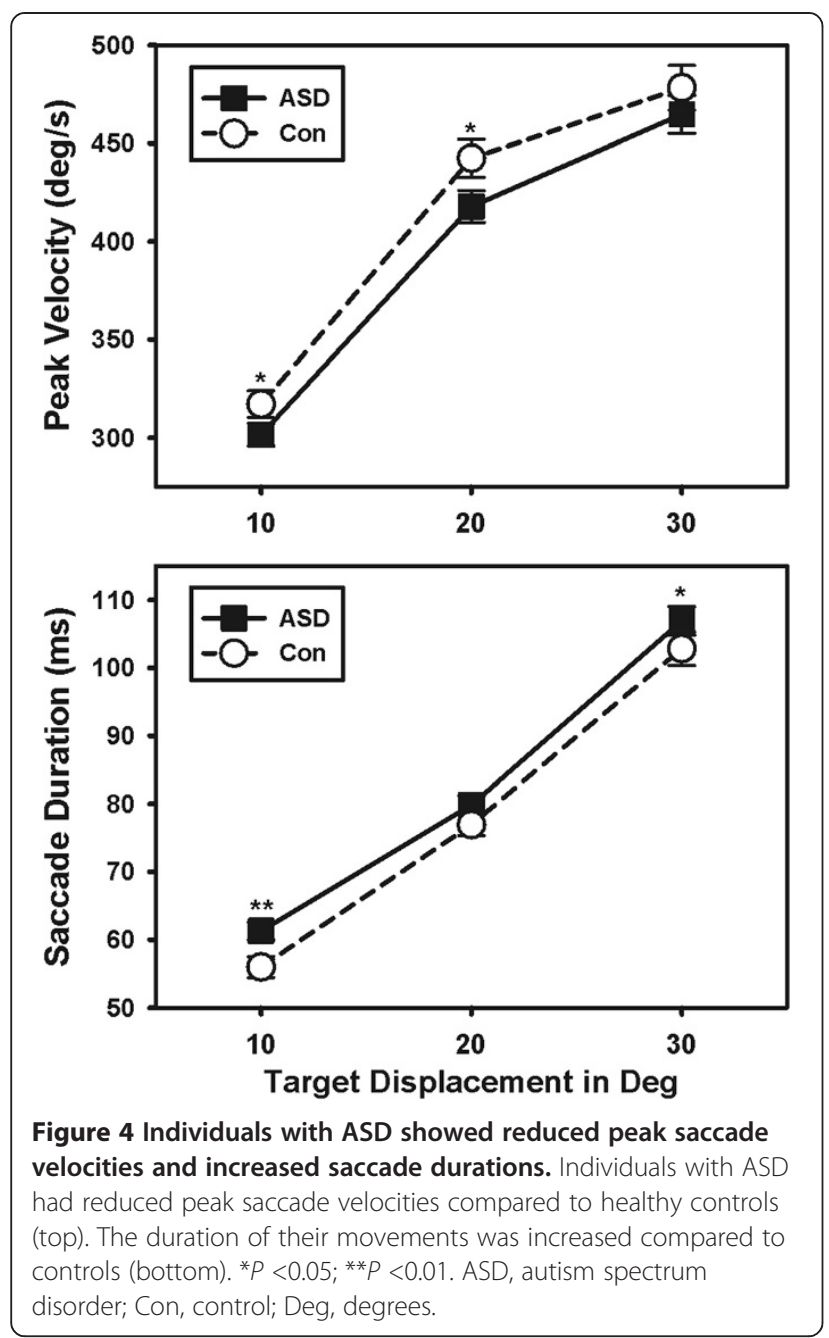

acceleration $(\mathrm{F}(1,99)<0.01 ; P=0.985)$ or peak deceleration $(\mathrm{F}(1,100)=1.91 ; P=0.170)$ across groups.

However, individuals with ASD took more time to accelerate saccades to peak velocity than controls (Figure 5; $F(1,104)=6.35 ; P=0.013)$. There was no group difference in the amount of time spent decelerating saccades (Figure $5 ; \quad F(1,104)=0.38 ; P=0.541$ ). Increased time spent accelerating saccades was not related to saccade accuracy (Additional file $1 ; \mathrm{r}=-0.18 ; P=0.354$ ) or variability of accuracy $(\mathrm{r}=-0.06 ; P=0.625)$ in ASD. However, increased time spent decelerating saccades was related to lower saccade error $(\mathrm{r}=-0.29 ; P=0.021)$ and less variability of saccade error in ASD $(\mathrm{r}=-0.26 ; P=0.039)$. Acceleration and deceleration durations were not related to accuracy measures in healthy controls (See Additional file 2). No group differences were found in the trial-wise variability of time spent accelerating $(\mathrm{F}(1,102=1.54 ; P=$ $0.217)$ or decelerating $(\mathrm{F}(1,102)=2.30 ; P=0.133)$ saccades.

Notably, impairments in saccade accuracy and saccade dynamics or the variability of these saccade measures were not significantly correlated in ASD (Additional files
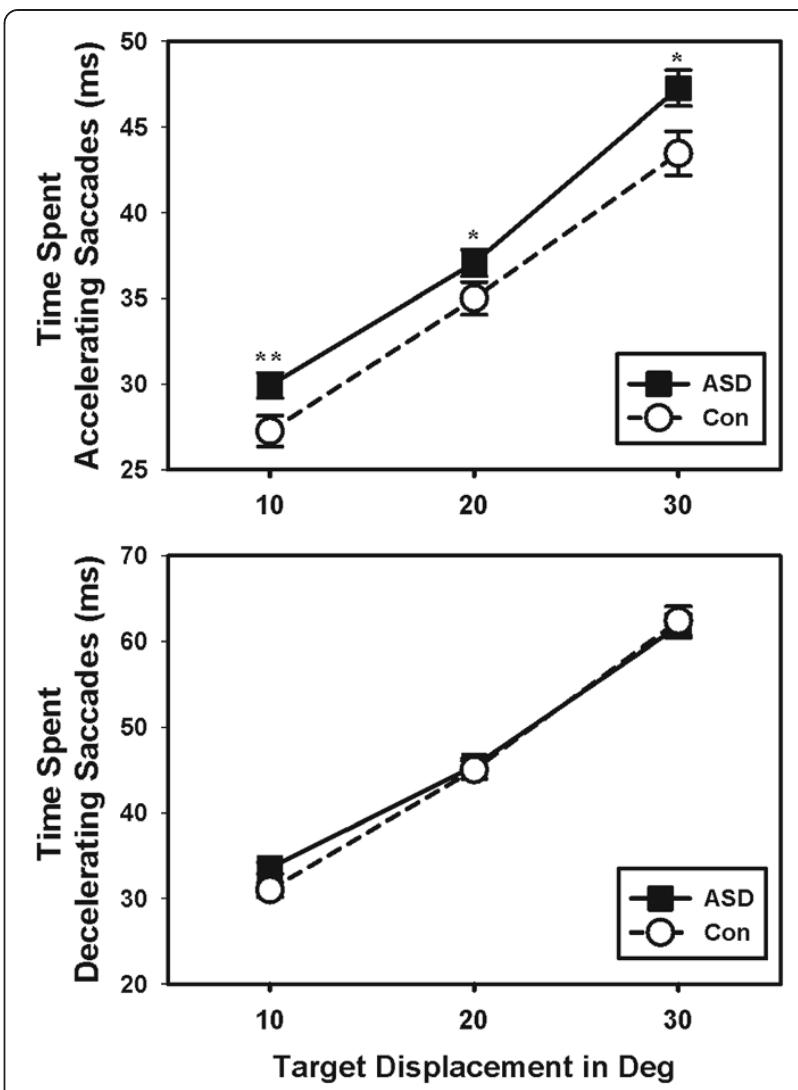

Figure 5 Individuals with ASD took longer to reach peak velocity than healthy controls. The time spent accelerating saccades was increased in ASD compared to healthy controls (top). Individuals with ASD showed similar durations of the deceleration phase of their saccades (bottom). ${ }^{*} P<0.05$; ${ }^{*} P<0.01$. ASD, autism spectrum disorder; Con, control; Deg, degrees.

1, 4 and 5). This suggests that different individuals with ASD express these two deficits separately, that alterations in brain systems regulating one saccade parameter is not the cause of dysfunction in the other, and that different brain systems are implicated by the two sets of abnormalities.

\section{Age-related changes in saccade accuracy and dynamics}

Age-related reductions in saccade error $(\mathrm{F}(2,100)=5.72$; $P=0.004)$, saccade error variability $(\mathrm{F}(2,99)=7.769 ; P=$ $0.001)$ and saccade amplitude variability $(\mathrm{F}(2,99)=5.484$; $P=0.006)$ were observed. Saccade latency $(F(2,100)=$ 11.794; $P<0.001)$ and saccade latency variability across trials $(\mathrm{F}(2,99)=15.634 ; P<0.001)$ were reduced with increasing age of participants.. None of the age-related improvements in saccade performance differed between participant groups (Additional files 6, 7, 8 and 9; P's > 0.384 ), suggesting that deficits of patients relative to agematched peers were relatively consistent across the age range studied. Saccade dynamics (such as velocity and 
duration) demonstrated no developmental change in either group ( $\left.P^{\prime} \mathrm{s}>0.176\right)$.

\section{Clinical correlations}

Saccade variables were not associated with intellectual functioning in either group $\left(P^{\prime} \mathrm{S}>0.081\right)$. In participants with ASD, no saccade variable was significantly associated with clinical ratings of ASD features on the ADI-R or ADOS $(P$ 's $>0.177)$.

\section{Discussion}

The present study examined visually-guided saccades to assess the functional integrity of cerebellar and brainstem sensorimotor systems and visual attention systems in ASD. Analyses revealed five key findings. First, participants with ASD demonstrated decreased accuracy of saccadic eye movements, and the accuracy of their saccades was more variable across trials. The increased variability in performance suggests a deficit in the cerebellar variability-reducing functions, leading to a reduced capacity for making compensatory adjustments to ensure consistent and accurate saccade execution. This replicates earlier findings [9,13-16] indicating functional disturbances within cerebellar systems controlling the accuracy and consistency of eye movement trajectories, an interpretation that is supported by recent observations of saccade adaptation abnormalities in ASD [47,48]. Second, peak saccade velocities were lower and durations were longer in participants with ASD. These abnormalities in peak velocity and duration suggest reduced pontine brainstem burst cell excitatory activity and/or increased omnipause cell inhibitory activity that alter the metrics of saccadic eye movements. These deficits were consistent across saccade amplitudes.

Third, patients spent more time accelerating saccades to reach peak velocity but not decelerating them. This abnormal eye movement activity has not been reported previously in ASD. It suggests poor temporal synchronization of burst cell and omnipause cell activity within pontine nuclei, with excessive inhibition or reduced excitatory drive in the early phase of saccade execution. A similar pattern of a protracted acceleration phase during finger movements has also been reported in ASD [72], thus abnormal input to multiple motor systems from the cerebellum could contribute to movement acceleration deficits across effector systems. Fourth, age-related improvements in saccade performance were similar across patient and control groups, suggesting a similar developmental profile of oculomotor function in ASD as in neurotypical individuals across the age span studied. Last, participants with ASD were not differentially impacted by gap and overlap conditions relative to controls, failing to provide evidence for an alteration in exogenous visual attentional systems in ASD. Mean response latencies also were unimpaired. Both of these observations are consistent with prior reports that automatic visual orienting attention systems are not impaired in ASD $[9,13,14,73]$. However, increased latency variability in participants with ASD does indicate increased variability in attentional control.

Our characterization of saccade deficits in ASD is more analogous to patterns seen in patients with ataxia than other common neurodevelopmental or neuropsychiatric disorders $[67,74]$. Individuals with spinocerebellar ataxia [75] and Friederich's ataxia [76] show a similar pattern of reduced velocity, increased duration and dysmetria as seen in our patients. Notably, however, prolonged saccade duration in these samples occurs in the deceleration phase, and so the pattern we observed is a distinct one. Evidence of impaired saccade accuracy has been reported in Reading Disorder [77] and Tourette's syndrome [78], but neither patient sample has been shown to have alternations in saccade dynamics. Thus, our findings of saccade deficits in ASD seem more indicative of a fundamental motor disturbance, rather than a problem of higher neurocognitive control.

\section{Saccade accuracy}

Consistent with previous reports by our group and others [9,13-15], we demonstrated saccade dysmetria in ASD. Four findings regarding our observation of reduced saccade accuracy are noteworthy. First, participants with ASD showed greater trial-to-trial variability in the accuracy of their saccades, indicating that increased variability in motor precision is present not only across affected individuals, but also within individual patients. Second, participants with ASD showed more pronounced dysmetria when making larger saccades, indicating that patients become more impaired when demands on the motor system are increased, a finding previously found by our group and others $[13,17,18]$.

Third, despite the increased saccade amplitude error, we found no evidence of reduced saccade amplitudes, in contrast to prior reports of hypometria in ASD [9,13-15]. Instead, our data demonstrated both hypometric and hypermetric saccades in ASD, with average saccade amplitude similar to that of healthy controls. The larger range of saccade amplitudes assessed and the use of multiple peripheral targets in the current study may contribute to the difference in our findings relative to previous studies. Fourth, despite an increase in error variability in ASD, the patient group did not demonstrate an increase in trial-totrial variability of the duration of saccade deceleration, reflecting a failure to use online feedback processes to reduce saccade error.

One mechanism whereby the cerebellum controls movement accuracy is via online adjustments to the duration of eye movements, which occurs primarily during the deceleration phase of the saccade [31]. Cerebellar projections originating in the oculomotor vermis and 
relayed via caudal fastigial nuclei innervate pontine burst and omnipause neurons to modulate saccade durations and amplitudes [29,79]. Thus, input from the cerebellum to the brainstem can reduce saccade error by providing a command to extend or reduce the duration of dysmetric movements so they end closer to the target location $[25,31,33,80,81]$. The observations that the trial-wise variability of saccade deceleration duration were not increased in ASD despite the increased variability in saccade accuracy suggests a reduced ability to either estimate expected error during saccade execution or to use those estimations to modify saccades in transit to reduce their spatial error.

Our findings thus indicate a deficit in the variabilityreducing function of the cerebellum in ASD, resulting in both hypometric and hypermetric saccades. Purkinje cells of the dorsal cerebellar vermis are the sole output of the cerebellar cortex, and these cells are known to play a major role in controlling endpoint accuracy of saccades $[33,82,83]$. Selective damage to the oculomotor vermis within the cerebellum (lobules VI to VII) produces increased trial-to-trial variability of saccades in both non-human primates and in clinical studies, similar to findings observed in the present study [27-29,31,84]. This neurobehavioral evidence of impaired variabilityreducing function in the cerebellum is consistent with postmortem studies documenting cerebellar histopathology in ASD, including reduced size and density of Purkinje cells [39,42,44-46].

\section{Saccade dynamics}

One possible explanation for the altered saccade velocity and duration, and the extended acceleration but not deceleration phase of the saccade in our ASD participants, is an imbalance of excitatory and inhibitory signaling in the pontine brainstem. Duration of activity in pontine burst neurons is tightly correlated with saccade duration [85] and likewise, firing rates of the burst neurons are highly related to peak saccade velocity [86]. Omnipause cells tonically inhibit burst cells prior to a saccadic eye movement, and then become active again to terminate the movement. The increased time to accelerate saccades thus implicates enhanced inhibitory activity of pontine omnipause cells, diminished excitatory activity of burst cells or a reduced ability to synchronize the onset and offset of excitatory and inhibitory signaling. Our observation of altered saccade accelerations is consistent with prior anatomical studies of individuals with ASD documenting hypoplasia and cellular pathology within pontine nuclei $[34,35]$. Although the brainstem is implicated by our data and prior ASD research, future studies are needed to confirm that the observed eye movement alternations directly result from brainstem abnormalities.

Alternatively, changes in altered saccade dynamics might result from abnormal upstream input to the pons from the superior colliculus, basal ganglia or cortical eye fields. Superior colliculus activity is known to influence saccade duration, peak velocity and acceleration [87-90], and also sends indirect input to pontine circuitry via the central mesencephalic reticular formation (cMRF) [24]. cMRF firing patterns regulate omnipause firing activity at the beginning and end of saccades [90]. Thus, it is possible that altered omnipause and burst cell firing rates may be a downstream effect of impairment within the superior colliculus, in its input or in the pathways between superior colliculus and excitatory and inhibitory pontine cells. While involvement of cortical eye fields and basal ganglia in these saccade dynamic abnormalities is possible, dysfunction in either region would be expected to have led to atypical gap/overlap effects, which were not seen in our study [24].

Another possibility is that the prolonged acceleration of eye movements could result from cerebellar dysfunction given the dense afferent and efferent projections between the cerebellum and pontine nuclei $[29,79,91,92]$. Greater feedforward drive from the cerebellum to pons might extend saccade acceleration, but in this case similar alterations during the deceleration phase would be expected and these were not presently seen. Also, the independence of saccade accuracy and all movement dynamics provides evidence for a dissociation of abnormalities in the cerebellum and brainstem systems in ASD, which indicates that abnormal cerebellar input is not likely to be the primary cause of pontine dysfunction.

\section{Developmental improvements}

Age-related improvements of saccade accuracy, saccade accuracy variability, saccade latency and saccade latency variability are consistent with prior findings in healthy control populations $[21,23,71]$. These findings are consistent with previous literature showing similar developmental trajectories of saccade latency $[14,93]$ and latency variability [93] in ASD and healthy control individuals across childhood and adolescence. Despite abnormalities of saccade accuracy and accuracy variability in ASD, individuals with ASD appear to benefit from developmental processes with a trajectory similar to that of healthy controls, at least in regard to the sensorimotor processes and age range examined in this study. Thus, these saccade abnormalities appear to reflect deficits emerging in childhood, if not earlier, that persist into adulthood. One implication of this pattern is that these deficits may be a useful biomarker for early detection but studies tracking these impairments to the first years of life are needed to characterize their onset and course.

\section{Clinical relationships}

We observed no significant relationships between saccade measures and clinical features of ASD. Oculomotor 
control is supported by cortico-cerebellar-brainstem circuits which are notably distinct from those believed relevant to the social communication deficits and restricted, repetitive behaviors in ASD. Thus, even though sensorimotor deficits are present in the majority of individuals with ASD, they may represent additional neural system dysfunctions in ASD bearing limited relationship to those impacting neural substrates related to the disorder's core diagnostic features. Furthermore, although we did not find evidence of a relationship between oculomotor dysfunctions and clinically-rated social communication abnormalities in ASD, it is possible that the observed alterations in saccade accuracy and dynamics are related to the ability to coordinate gaze during social interactions or when processing faces, as suggested by previous eye-tracking studies $[6,7]$. Reduced ability to consistently modulate saccadic eye movement amplitudes could negatively impact early social experiences, which could have downstream effects on social and cognitive developments $[8,94]$.

\section{Conclusions}

This study provides novel evidence that the accuracy and dynamics of visually-guided saccades are abnormal in ASD, implicating both cerebellum and brainstem systems in this disorder. Our findings are distinct from those that have been reported in other common neurodevelopmental and neuropsychiatric disorders, suggesting that these deficits may be unique to ASD, and provide biomarkers and/or endophenotypes for future research into this heterogeneous disorder. Our neurophysiological and functional observations are consistent with previous anatomic evidence from in vivo morphometric and postmortem studies that have demonstrated abnormalities in cerebellar and brainstem regions. Compromised cerebellar and brainstem function suggest that neural systems other than those related to key diagnostic features of ASD are affected in this disorder. These may lead to sensorimotor coordination impairments which impact on multiple aspects of day-to-day functioning [95].

\section{Additional files}

Additional file 1: Table S1. Relationships between saccade parameters for participants with ASD. Correlations of primary saccade parameters for participants with ASD.

Additional file 2: Table S2. Relationships between mean saccade parameters for healthy controls. Correlations of primary saccade parameters for healthy control participants.

Additional file 3: Figure S1. Main sequence relationships between peak saccade velocity and amplitude (top) and saccade duration and amplitude (bottom). Participants with ASD and healthy controls demonstrated similar slopes of the saccade main sequence for both parameters. Abnormalities observed in saccade velocity and duration thus appear to be consistent across saccade amplitudes in ASD.

Additional file 4: Table S3. Relationships between saccade performance variability (SD) across variables for participants with ASD.
Correlations of the variability of primary saccade parameters for participants with ASD.

Additional file 5: Table S4. Relationships between saccade performance variability (SD) across variables for healthy controls. Correlations of the variability of primary saccade parameters for healthy control participants.

Additional file 6: Table S5. Saccade accuracy and latencies during gap trials for participants with ASD and healthy controls. Saccade accuracy and latency variables during gap trials are presented for each participant group and age group.

Additional file 7: Table S6. Saccade accuracy and latencies during overlap trials for participants with ASD and healthy controls. Saccade accuracy and latency variables during overlap trials are presented for each participant group and age group.

Additional file 8: Table S7. Saccade dynamics during gap trials for participants with ASD and healthy controls. Saccade dynamic variables during gap trials are presented for each participant group and age group.

Additional file 9: Table S8. Saccade dynamics during overlap trials for participants with ASD and healthy controls. Saccade dynamic variables during overlap trials are presented for each participant group and age group.

\section{Abbreviations}

ADI-R: Autism Diagnostic Interview-Revised; ADOS: Autism Diagnostic Observation Schedule; ASD: Autism spectrum disorder; CMRG: central mesencephalic reticular formation; EOG: Electro-oculography; IQ: Intelligence quotient; MRI: Magnetic resonance imaging; PDD-NOS: Pervasive

Development Disorder-Not Otherwise Specified.

\section{Competing interests}

JAS consults to Pfizer, Takeda, Roche, BMS and Lilly and had an investigator initiated grant from Janssen. EHC consults to Seaside Therapeutics and received grant (209AS208 and 209AS209) support from them.

\section{Authors' contributions}

LMS was involved in collecting, analyzing and interpreting data and drafting the manuscript. EHC provided consultation for data interpretation and was involved in revising the manuscript. JAS was involved in the conception and design of the experiment, providing consultation for data interpretation and critically revising the manuscript. MWM provided consultation for data interpretation and was involved in critically revising the manuscript. All authors read and approved the final manuscript.

\section{Acknowledgements}

This work was supported by NIH Autism Center of Excellence grant P50HD055751 (EHC, JAS, MWM), NIH K23 Research Career Development Award MH092696 (MWM) and an Autism Speaks grant 4853 (MWM).

\section{Author details}

${ }^{1}$ Center for Autism and Developmental Disabilities, University of Texas Southwestern, 5323 Harry Hines Blvd, Dallas, TX 75390-9086, USA.

2Department of Psychiatry, University of Illinois at Chicago, 1747 W. Roosevelt Rd (MC 747), Chicago, IL 60608, USA. ${ }^{3}$ Centre for Autism Spectrum Disorders, Bond University, Gold Coast, QLD 4229, Australia. ${ }^{4}$ Departments of Psychiatry and Pediatrics, University of Texas Southwestern Medical Center, 5323 Harry Hines Blvd, Dallas, TX 75390-9086, USA.

Received: 5 May 2014 Accepted: 28 August 2014

Published: 16 September 2014

\section{References}

1. American Psychiatric Association: Diagnostic and Statistical Manual of Mental Disorders. 5th edition. Washington, DC: American Psychiatric Publishing; 2013.

2. Ozonoff S, Heung K, Byrd R, Hansen R, Hertz-Picciotto I: The onset of autism: patterns of symptom emergence in the first years of life. Autism Res 2008, 1:320-328.

3. Zwaigenbaum L, Bryson S, Rogers T, Roberts W, Brian J, Szatmari P: Behavioral manifestations of autism in the first year of life. Int J Dev Neurosci 2005, 23:143-152. 
4. Elison JT, Paterson SJ, Wolff JJ, Reznick JS, Sasson NJ, Gu H, Botteron KN, Dager SR, Estes AM, Evans AC, Gerig G, Hazlett HC, Schultz RT, Styner M, Zwaigenbaum L, Piven J: White matter microstructure and atypical visual orienting in 7-month-olds at risk for autism. Am J Psychiatry 2013, 170:899-908.

5. Wolff JJ, Botteron KN, Dager SR, Elison JT, Estes AM, Gu H, Hazlett HC, Pandey J, Paterson SJ, Schultz RT, Zwaigenbaum L, Piven J: Longitudinal patterns of repetitive behavior in toddlers with autism. $J$ Child Psychol Psychiatry 2014, 55:945-953.

6. Klin A, Jones W, Schultz R, Volkmar F, Cohen D: Visual fixation patterns during viewing of naturalistic social situations as predictors of social competence in individuals with autism. Arch Gen Psychiatry 2002, 59:809-816.

7. Pelphrey KA, Sasson NJ, Reznick JS, Paul G, Goldman BD, Piven J: Visual scanning of faces in autism. J Autism Dev Disord 2002, 32:249-261.

8. Jones W, Klin A: Attention to eyes is present but in decline in 2-6-monthold infants later diagnosed with autism. Nature 2013, 504:427-431.

9. Takarae Y, Minshew NJ, Luna B, Sweeney JA: Oculomotor abnormalities parallel cerebellar histopathology in autism. J Neurol Neurosurg Psychiatry 2004, 75:1359-1361.

10. Takarae Y, Minshew NJ, Luna B, Krisky CM, Sweeney JA: Pursuit eye movement deficits in autism. Brain 2004, 127:2584-2594.

11. Takarae Y, Minshew NJ, Luna B, Sweeney JA: Atypical involvement of frontostriatal systems during sensorimotor control in autism. Psychiatry Res 2007, 156:117-127.

12. Mercadante MT, Macedo EC, Baptista PM, Paula CS, Schwartzman JS: Saccadic movements using eye-tracking technology in individuals with autism spectrum disorders: pilot study. Arq Neuropsiquiatr 2006, 64:559-562.

13. Johnson BP, Rinehart NJ, Papadopoulos N, Tonge B, Millist L, White O, Fielding J: A closer look at visually guided saccades in autism and Asperger's disorder. Front Integr Neurosci 2012, 6:99.

14. Luna B, Doll SK, Hegedus SJ, Minshew NJ, Sweeney JA: Maturation of executive function in autism. Biol Psychiatry 2007, 61:474-481.

15. Rosenhall U, Johansson E, Gillberg C: Oculomotor findings in autistic children. J Laryngol Otol 1988, 102:435-439.

16. Stanley-Cary C, Rinehart N, Tonge B, White O, Fielding J: Greater disruption to control of voluntary saccades in autistic disorder than Asperger's disorder: evidence for greater cerebellar involvement in autism? Cerebellum 2011, 10:70-80.

17. Mosconi MW, Kay M, D'Cruz AM, Guter S, Kapur K, Macmillan C, Stanford LD, Sweeney JA: Neurobehavioral abnormalities in first-degree relatives of individuals with autism. Arch Gen Psychiatry 2010, 67:830-840.

18. Minshew NJ, Luna B, Sweeney JA: Oculomotor evidence for neocortical systems but not cerebellar dysfunction in autism. Neurology 1999, 52:917-922

19. Pensiero S, Fabbro F, Michieletto P, Accardo A, Brambilla P: Saccadic characteristics in autistic children. Funct Neuro/ 2009, 24:153-158.

20. Sweeney JA, Mintun MA, Kwee S, Wiseman MB, Brown DL, Rosenberg DR, Carl JR: Positron emission tomography study of voluntary saccadic eye movements and spatial working memory. J Neurophysiol 1996, 75:454-468.

21. Munoz DP, Broughton JR, Goldring JE, Armstrong IT: Age-related performance of human subjects on saccadic eye movement tasks. Exp Brain Res 1998, 121:391-400.

22. Fukushima J, Hatta T, Fukushima K: Development of voluntary control of saccadic eye movements. I. Age-related changes in normal children. Brain Dev 2000, 22:173-180.

23. Irving EL, Steinbach MJ, Lillakas L, Babu RJ, Hutchings N: Horizontal saccade dynamics across the human life span. Invest Ophthalmol Vis Sci 2006, 47:2478-2484

24. Leigh RJ, Zee DS: The Neurology of Eye Movements. 4th edition. New York: Oxford University Press; 2006.

25. Robinson DA: Tectal oculomotor connections. Neurosci Res Program Bull $1975,13: 238-244$.

26. Fuchs AF, Kaneko CR, Scudder CA: Brainstem control of saccadic eye movements. Annu Rev Neurosci 1985, 8:307-337.

27. Ritchie L: Effects of cerebellar lesions on saccadic eye movements. J Neurophysiol 1976, 39:1246-1256.

28. Takagi M, Zee DS, Tamargo RJ: Effects of lesions of the oculomotor vermis on eye movements in primate: saccades. J Neurophysiol 1998, 80:1911-1931.

29. Noda H, Sugita S, Ikeda Y: Afferent and efferent connections of the oculomotor region of the fastigial nucleus in the macaque monkey. J Comp Neurol 1990, 302:330-348
30. Vilis T, Hore J: Characteristics of saccadic dysmetria in monkeys during reversible lesions of medial cerebellar nuclei. J Neurophysiol 1981 46:828-838.

31. Robinson FR, Straube A, Fuchs AF: Role of the caudal fastigial nucleus in saccade generation. II effects of muscimol inactivation. J Neurophysiol 1993, 70:1741-1758.

32. Golla H, Tziridis K, Haarmeier T, Catz N, Barash S, Thier P: Reduced saccadic resilience and impaired saccadic adaptation due to cerebellar disease. Eur J Neurosci 2008, 27:132-144.

33. Fuchs AF, Robinson FR, Straube A: Role of the caudal fastigial nucleus in saccade generation. I. Neuronal discharge pattern. J Neurophysiol 1993, 70:1723-1740.

34. Gaffney GR, Kuperman S, Tsai LY, Minchin S: Morphological evidence for brainstem involvement in infantile autism. Biol Psychiatry 1988, 24:578-586.

35. Hashimoto T, Tayama M, Miyazaki M, Murakawa K, Sakurama N, Yoshimoto T, Kuroda Y: Reduced midbrain and pons size in children with autism. Tokushima J Exp Med 1991, 38:15-18.

36. Hashimoto T, Tayama M, Miyazaki M, Murakawa K, Kuroda Y: Brainstem and cerebellar vermis involvement in autistic children. J Child Neurol 1993, 8:149-153.

37. Hashimoto T, Tayama M, Murakawa K, Yoshimoto T, Miyazaki M, Harada M, Kuroda Y: Development of the brainstem and cerebellum in autistic patients. J Autism Dev Disord 1995, 25:1-18.

38. Jou RJ, Frazier TW, Keshavan MS, Minshew NJ, Hardan AY: A two-year longitudinal pilot MRI study of the brainstem in autism. Behav Brain Res 2013, 251:163-167.

39. Bauman M, Kemper TL: Histoanatomic observations of the brain in early infantile autism. Neurology 1985, 35:866-874.

40. Bauman ML, Kemper TL: Neuroanatomic observations of the brain in autism: a review and future directions. Int J Dev Neurosci 2005, 23:183-187.

41. Ritvo ER, Freeman BJ, Scheibel AB, Duong T, Robinson H, Guthrie D, Ritvo A Lower purkinje cell counts in the cerebella of four autistic subjects: initial findings of the UCLA-NSAC autopsy research report. Am J Psychiatry 1986 143:862-866.

42. Wegiel J, Kuchna I, Nowicki K, Imaki H, Ma SY, Azmitia EC, Banerjee P, Flory M, Cohen IL, London E, Brown WT, Komich Hare C, Wisniewski T: Contribution of olivofloccular circuitry developmental defects to atypical gaze in autism. Brain Res 2013, 1512:106-122.

43. Bauman ML: Microscopic neuroanatomic abnormalities in autism. Pediatrics 1991, 87:791-796.

44. Rojas DC, Peterson E, Winterrowd E, Reite ML, Rogers SJ, Tregellas JR: Regional gray matter volumetric changes in autism associated with social and repetitive behavior symptoms. BMC Psychiatry 2006, 6:56.

45. Courchesne E, Saitoh O, Yeung-Courchesne R, Press GA, Lincoln AJ, Haas $\mathrm{RH}$, Schreibman L: Abnormality of cerebellar vermian lobules VI and VII in patients with infantile autism: identification of hypoplastic and hyperplastic subgroups with MR imaging. AJR Am J Roentgenol 1994, 162:123-130.

46. Courchesne $E$, Yeung-Courchesne R, Press GA, Hesselink JR, Jernigan TL: Hypoplasia of cerebellar vermal lobules VI and VII in autism. N Engl J Med 1988, 318:1349-1354

47. Mosconi MW, Luna B, Kay-Stacey M, Nowinski CV, Rubin LH, Scudder C, Minshew N, Sweeney JA: Saccade adaptation abnormalities implicate dysfunction of cerebellar-dependent learning mechanisms in Autism Spectrum Disorders (ASD). PLoS One 2013, 8:e63709.

48. Johnson BP, Rinehart NJ, White O, Millist L, Fielding J: Saccade adaptation in autism and Asperger's disorder. Neuroscience 2013, 243:76-87.

49. Corbetta M, Akbudak E, Conturo TE, Snyder AZ, Ollinger JM, Drury HA, Linenweber MR, Petersen SE, Raichle ME, Van Essen DC, Shulman GL: A common network of functional areas for attention and eye movements. Neuron 1998, 21:761-773

50. Moore T, Fallah M: Control of eye movements and spatial attention. Proc Natl Acad Sci U S A 2001, 98:1273-1276

51. Fischer $B$, Breitmeyer $B$ : Mechanisms of visual attention revealed by saccadic eye movements. Neuropsychologia 1987, 25:73-83.

52. Reuter-Lorenz PA, Hughes HC, Fendrich R: The reduction of saccadic latency by prior offset of the fixation point: an analysis of the gap effect. Percept Psychophys 1991, 49:167-175.

53. Klein RM, Taylor TL, Kingstone A: Against a role for attentional disengagement in the gap effect: a friendly amendment to Tam and Stelmach (1993). Percept Psychophys 1995, 57:573-577. 
54. Goldberg MC, Lasker AG, Zee DS, Garth E, Tien A, Landa RJ: Deficits in the initiation of eye movements in the absence of a visual target in adolescents with high functioning autism. Neuropsychologia 2002, 40:2039-2049.

55. van der Geest JN, Kemner C, Camfferman G, Verbaten MN, van Engeland H: Eye movements, visual attention, and autism: a saccadic reaction time study using the gap and overlap paradigm. Biol Psychiatry 2001, 50:614-619.

56. Munson J, Dawson G, Sterling L, Beauchaine T, Zhou A, Elizabeth K, Lord C, Rogers S, Sigman M, Estes A, Abbott R: Evidence for latent classes of IQ in young children with autism spectrum disorder. Am J Ment Retard 2008, 113:439-452.

57. Joseph RM, Tager-Flusberg H, Lord C: Cognitive profiles and socialcommunicative functioning in children with autism spectrum disorder. J Child Psychol Psychiatry 2002, 43:807-821.

58. Siegel DJ, Minshew NJ, Goldstein G: Wechsler IQ profiles in diagnosis of high-functioning autism. J Autism Dev Disord 1996, 26:389-406.

59. Lord C, Rutter M, Le Couteur A: Autism diagnostic interview-revised: a revised version of a diagnostic interview for caregivers of individuals with possible pervasive developmental disorders. J Autism Dev Disord 1994, 24:659-685.

60. Lord C, Risi S, Lambrecht L, Cook EH Jr, Leventhal BL, DiLavore PC, Pickles A, Rutter M: The autism diagnostic observation schedule-generic: a standard measure of social and communication deficits associated with the spectrum of autism. J Autism Dev Disord 2000, 30:205-223.

61. Gotham K, Risi S, Pickles A, Lord C: The Autism Diagnostic Observation Schedule: revised algorithms for improved diagnostic validity. J Autism Dev Disord 2007, 37:613-627.

62. Berument SK, Rutter M, Lord C, Pickles A, Bailey A: Autism screening questionnaire: diagnostic validity. Br J Psychiatry 1999, 175:444-451.

63. Reilly JL, Lencer R, Bishop JR, Keedy S, Sweeney JA: Pharmacological treatment effects on eye movement control. Brain Cogn 2008, 68:415-435.

64. Elliott CD: Differential Ability Scales, 2nd Edition: Introductory and Technical Handbook. San Antonio, Texas: The Psychological Corporation; 2007.

65. Wechsler D: Wechsler Abbreviated Scale of Intelligence. San Antonio, Texas: The Psychological Corporation; 1999.

66. Harris MS, Reilly UL, Thase ME, Keshavan MS, Sweeney JA: Response suppression deficits in treatment-naive first-episode patients with schizophrenia, psychotic bipolar disorder and psychotic major depression. Psychiatry Res 2009, 170:150-156.

67. Reilly JL, Harris MS, Keshavan MS, Sweeney JA: Abnormalities in visually guided saccades suggest corticofugal dysregulation in never-treated schizophrenia. Biol Psychiatry 2005, 57:145-154.

68. Sweeney JA, Bauer KS, Keshavan MS, Haas GL, Schooler NR, Kroboth PD: Adverse effects of risperidone on eye movement activity: a comparison of risperidone and haloperidol in antipsychotic-naive schizophrenic patients. Neuropsychopharmacology 1997, 16:217-228.

69. Rosenberg DR, Dick EL, O'Hearn KM, Sweeney JA: Response-inhibition deficits in obsessive-compulsive disorder: an indicator of dysfunction in frontostriatal circuits. J Psychiatry Neurosci 1997, 22:29-38.

70. Bahill AT, Clark MR, Stark L: The main sequence, a tool for studying human eye movements. Math Biosci 1975, 24:191-204.

71. Luna B, Garver KE, Urban TA, Lazar NA, Sweeney JA: Maturation of cognitive processes from late childhood to adulthood. Child Dev 2004 75:1357-1372

72. Glazebrook CM, Elliott D, Lyons J: A kinematic analysis of how young adults with and without autism plan and control goal-directed movements. Mot Control 2006, 10:244-264.

73. Kylliainen A, Hietanen JK: Attention orienting by another's gaze direction in children with autism. J Child Psychol Psychiatry 2004, 45:435-444.

74. Munoz DP, Armstrong IT, Hampton KA, Moore KD: Altered control of visual fixation and saccadic eye movements in attention-deficit hyperactivity disorder. J Neurophysiol 2003, 90:503-514.

75. Federighi P, Cevenini G, Dotti MT, Rosini F, Pretegiani E, Federico A, Rufa A Differences in saccade dynamics between spinocerebellar ataxia 2 and late-onset cerebellar ataxias. Brain 2011, 134:879-891.

76. Kirkham TH, Guitton D, Katsarkas A, Kline LB, Andermann E: Oculomotor abnormalities in Friedreich's ataxia. Can J Neurol Sci 1979, 6:167-172.

77. Eden GF, Stein JF, Wood HM, Wood FB: Differences in eye movements and reading problems in dyslexic and normal children. Vision Res 1994, 34:1345-1358
78. Narita AS, Shawkat FS, Lask B, Taylor DS, Harris CM: Eye movement abnormalities in a case of Tourette syndrome. Dev Med Child Neurol 1997, 39:270-273

79. Scudder CA, Kaneko CS, Fuchs AF: The brainstem burst generator for saccadic eye movements: a modern synthesis. Exp Brain Res 2002, 142:439-462.

80. Ohtsuka K, Noda H: Burst discharges of mossy fibers in the oculomotor vermis of macaque monkeys during saccadic eye movements. Neurosci Res 1992, 15:102-114.

81. Pelisson D, Prablanc C: Kinematics of centrifugal and centripetal saccadic eye movements in man. Vision Res 1988, 28:87-94.

82. Ohtsuka K, Noda H: Saccadic burst neurons in the oculomotor region of the fastigial nucleus of macaque monkeys. J Neurophysiol 1991, 65:1422-1434.

83. Ohtsuka K, Noda H: Direction-selective saccadic-burst neurons in the fastigial oculomotor region of the macaque. Exp Brain Res 1990, 81:659-662.

84. Barash S, Melikyan A, Sivakov A, Zhang M, Glickstein M, Thier P: Saccadic dysmetria and adaptation after lesions of the cerebellar cortex. J Neurosci 1999, 19:10931-10939.

85. Luschei ES, Fuchs AF: Activity of brain stem neurons during eye movements of alert monkeys. J Neurophysiol 1972, 35:445-461.

86. Van Gisbergen JA, Robinson DA, Gielen S: A quantitative analysis of generation of saccadic eye movements by burst neurons. J Neurophysiol 1981, 45:417-442

87. Goossens HH, van Opstal AJ: Optimal control of saccades by spatialtemporal activity patterns in the monkey superior colliculus. PLoS Comput Biol 2012, 8:e1002508.

88. Hikosaka O, Wurtz RH: Saccadic eye movements following injection of lidocaine into the superior colliculus. Exp Brain Res 1986, 61:531-539.

89. Albano JE, Wurtz RH: Deficits in eye position following ablation of monkey superior colliculus, pretectum, and posterior-medial thalamus. J Neurophysiol 1982, 48:318-337.

90. Wang N, Perkins E, Zhou L, Warren S, May PJ: Anatomical evidence that the superior colliculus controls saccades through central mesencephalic reticular formation gating of omnipause neuron activity. J Neurosci 2013, 33:16285-16296.

91. Scudder CA, Moschovakis AK, Karabelas AB, Highstein SM: Anatomy and physiology of saccadic long-lead burst neurons recorded in the alert squirrel monkey. II. Pontine neurons. J Neurophysiol 1996, 76:353-370.

92. Batini C, Buisseret-Delmas C, Corvisier J, Hardy O, Jassik-Gerschenfeld D: Brain stem nuclei giving fibers to lobules VI and VII of the cerebellar vermis. Brain Res 1978, 153:241-261.

93. Ego C, de Xivry JJO, Nassogne MC, Yuksel D, Lefevre P: The saccadic system does not compensate for the immaturity of the smooth pursuit system during visual tracking in children. J Neurophysiol 2013, 110:358-367.

94. Dawson G, Toth K, Abbott R, Osterling J, Munson J, Estes A, Liaw J: Early social attention impairments in autism: social orienting, joint attention, and attention to distress. Dev Psychol 2004, 40:271-283.

95. Kirby A, Sugden D, Purcell C: Diagnosing developmental coordination disorders. Arch Dis Child 2014, 99:292-296.

doi:10.1186/2040-2392-5-47

Cite this article as: Schmitt et al:: Saccadic eye movement abnormalities in autism spectrum disorder indicate dysfunctions in cerebellum and brainstem. Molecular Autism 2014 5:47.

\section{Submit your next manuscript to BioMed Central and take full advantage of:}

- Convenient online submission

- Thorough peer review

- No space constraints or color figure charges

- Immediate publication on acceptance

- Inclusion in PubMed, CAS, Scopus and Google Scholar

- Research which is freely available for redistribution 